\title{
Health-related quality of life in elderly, multimorbid individuals with and without depression and/or mild cognitive impairment using a telemonitoring application
}

\author{
Caroline Lang $^{1}$ (D) Martin Roessler ${ }^{1}$ (D) . Jochen Schmitt ${ }^{1} \cdot$ Antje Bergmann $^{2} \cdot$ Vjera Holthoff-Detto $^{3,4}$
}

Accepted: 14 April 2021 / Published online: 13 May 2021

(C) The Author(s) 2021

\begin{abstract}
Purpose Multimorbidity leads to decreasing health-related quality of life (HRQoL). Telemedicine may help to improve HRQoL. The present study was conducted to show (I) differences in HRQoL and changes in HRQoL over time in elderly, multimorbid individuals with and without depression and/or mild cognitive impairment (MCI) using a telemonitoring application (TMA) and (II) associations between engagement with measurements by study participants using a TMA and changes in their HRQoL.

Methods The present feasibility study was part of a longitudinal intervention study. Recruited general practitioners (GPs) enrolled individuals and assigned them to risk groups according to absence/presence of depression and/or MCI. Depression was assessed using the Geriatric Depression Scale (GDS-15), MCI using the Mini-Mental State Examination (MMSE), and HRQoL using the SF-12. The TMA consisted of tablets, software, and measuring devices. Measured vital data were transferred to a care and case manager for monitoring and possible intervention.

Results Nine GPs recruited 177 individuals, 97 of whom were included in the HRQoL analysis. Significantly lower physical and mental component summary (PCS/MCS) scores were revealed in study participants with depression, and with both depression and MCI, compared to participants with no mental disorders. PCS scores did not differ between study dates, but MCS scores had significantly increased over time. Participants' engagement with measurements was significantly associated with an increased MCS score, but not with the PCS score.

Discussion Depression and/or MCI are negatively associated with the HRQoL of elderly, multimorbid people using a TMA. Engagement of individuals with vital data measurements via a TMA may increase their mental HRQoL. Mentally impaired people should be closely involved as co-designers and experts in development processes of TMAs to benefit from tailored solutions. An individual's increased mental HRQoL can be a decisive factor in their engagement with a GP treatment regimen and telemonitoring processes.
\end{abstract}

Keywords Telemedicine $\cdot$ Telehealth $\cdot$ Quality of life $\cdot$ Mental disorders $\cdot$ Multimorbidity $\cdot$ Aged

Caroline Lang

caroline.lang@ukdd.de

1 Center for Evidence-Based Healthcare, University Hospital and Faculty of Medicine Carl Gustav Carus, Technische Universität Dresden, Fetscherstraße 74, 01307 Dresden, Germany

2 Department of General Practice, Medical Clinic III, Faculty of Medicine Carl Gustav Carus, Technische Universität Dresden, Dresden, Germany
3 Department of Psychiatry, Psychotherapy and Psychosomatics, Alexianer Hospital Hedwigshöhe, St. Hedwig Hospital Berlin, Berlin, Germany

4 Department of Psychiatry and Psychotherapy, University Hospital Carl Gustav Carus, Technische Universität Dresden, Dresden, Germany 


\section{Introduction}

Multimorbidity is a highly prevalent global health problem in elderly individuals $[1,2]$. It is defined as the simultaneous occurrence of two or more diseases in the same person [2, 3]. More severe and prolonged chronic diseases can lead to increased physical and mental suffering of elderly people [2]. The resulting consequences can be a significant increase of health care utilization, health care costs, functional impairment, and a poor quality of life [2, 4]. Multimorbidity is associated with a high level of physical suffering and reduced health-related quality of life (HRQoL) [5]. HRQoL, as a multidimensional construct, assesses the subjectively perceived health status of individuals within a holistic approach — not only on the physical dimension, but also regarding psychological and social facets [6]. As a patient-reported outcome (PRO), HRQoL is increasingly assessed to explore the needs and concerns of individuals, to strengthen the relationship between individuals and physicians, and to enhance shared decision making [7, 8], especially in vulnerable individuals with chronic diseases [9]. HRQoL can be measured using generic measuring instruments (patient-reported outcome measures (PROMs)), such as the Short Form-36 (SF-36) or SF-12, with the two main dimensions of physical health component summary (PCS) score and mental health component summary (MCS) score [8]. The use of PROMs in health care aims to ensure targeted and needs-based care, e.g. recognizing and treating deterioration in individuals' health more quickly. Furthermore it aims to increase HRQoL and satisfaction of individuals by reflecting their needs and concerns [8, 9].

Results of previous studies with elderly people from different countries indicated that an increase in the number of chronic diseases in an individual is associated with a reduced HRQoL [5, 10-12]. In order to regain and maintain HRQoL, telemedicine can beneficially complement the health care routine of elderly, multimorbid individuals [13]. Telemedicine enables healthcare providers to communicate with each other or with the people across spatial and temporal distances with the aim to improve health outcomes by providing information on diagnostics, therapy, rehabilitation, prevention, research and medical decision making in various settings [14, 15]. National and international studies have already shown that telemedicine applications for highly prevalent diseases such as cardiovascular and respiratory diseases as well as cardiometabolic disorders can help to reduce treatment costs and hospitalization rates and to improve individuals' HRQoL [16-18]. However, existing results are mixed regarding effects of home telemonitoring applications on HRQoL in elderly people with chronic diseases. Results from randomized controlled trials (RCTs) with elderly multimorbid people using a telemonitoring system showed improvements in HRQoL in study participants [19-22], although other telemonitoring RCTs could not achieve congruent results [23-26]. There is also evidence that the effects of telemonitoring on those with mental disorders, such as depression and mild cognitive impairment (MCI), can be promising [27-29]. A longitudinal telemonitoring study in which study participants had to take weekly vital sign measurements detected significant improvements in depression and HRQoL scores [27]. A significant reduction in depressive symptoms in the intervention group compared to the control group could be shown in a telemonitoring RCT with medically frail and homebound individuals [30]. Insignificant changes in HRQoL in study participants with MCI were determined in a telemonitoring study using a quasiexperimental design [31].

HRQoL can be positively influenced by individuals' engagement with telemonitoring measures. In the present context, participant engagement with measurements via the telemonitoring application (TMA) is defined as the active and exact measurement of vital data via home telemonitoring devices by participants according to the treatment regimen of the responsible general practitioner. An exact measuring behavior of participants will henceforth be referred to as "exact".

As reported from intervention studies, observation studies, and mixed-methods studies, study participants were highly satisfied with the use of telemedicine applications, and acceptance and adherence were positively rated [32-34]. Adherence of elderly people was reported as being generally higher than in younger individuals [35, 36] and higher adherence rates in male than female study participants were detected [36, 37], with no difference between age groups [37]. Results of systematic reviews showed that telemonitoring for people with MCI has so far focused particularly on technologies that ensure an independent and safe life at home [38, 39] and support their informal and formal caregivers in monitoring affected individuals so they can stay safe at home [40, 41]. Smith et al. reported results from a home telemonitoring study with a small number of elderly people suffering from MCI [42]. The authors concluded that telemonitoring can be beneficial for individuals with MCI. In spite of 10-15\% of study participants who failed to respond to the telemonitoring equipment due to their still active and independent status, adherence to the telemonitoring regimen of study participants who were assigned to the intervention group was stable and their mood had improved [42]. Holthe et al. pointed out that the currently existing evidence on the acceptance of assistive technologies for people with MCI is low, which could be due to the difficulty of assessing the measurement results [39]. 


\section{Aims of study and research questions}

The overall study "Autonomy despite multimorbidity in Saxony through patient empowerment, holistic care for older people with networking of all regional institutions and service providers" (Acronym: ATMoSPHAERE) contributed to the care of elderly, multimorbid people. A significant challenge is the feasible identification of risk groups within the cohort of participants for whom it could be difficult to use telemonitoring measures. These include individuals with MCI or depression-a patient cohort that was excluded or underrepresented in previous studies [43], although the afflicted suffer from the most common diseases of old age. Supported by professionals in the fields of primary care, geriatric medicine, information technology, social services and economics, a regional ecosystem was created that combined both medical and non-medical services on the basis of a medical technology platform. Cross-sectoral networking enabled e.g. the coordination, optimization and rapid adjustment of care plans and the recording of patient needs. Thus, a comprehensive care concept for elderly, multimorbid individuals was developed, which included aspects of prevention, diagnosis, therapy and aftercare/rehabilitation. Its aim was to enable people to lead a largely self-determined life by controlling their own disease-related restrictions. The increase in HRQoL of the study participants (in the following referred to as "participants"), measured with the SF-12, was defined as a secondary outcome in the study [44, 45]. Participants were provided with a TMA, which enabled them to measure vital signs, transfer these data to a care coordination center, and to request home-based assistance and services from regional providers.

\section{The research questions of the present analysis were:}

(a) Were there differences in HRQoL and changes in HRQoL over the course of TMA usage between participants with and without depression and/or MCI?

(b) Was engagement with measurements by participants using the telemonitoring application associated with a change in HRQoL scores?

\section{Methods}

The ATMoSPHAERE study was funded by the German Federal Ministry of Education and Research (grant number 13GW0075F) and was carried out between October 2015 and June 2019. Participant enrollment started in April 2016; the last participant was enrolled in March 2018, with followup data being collected until June 2018.

\section{Study design and study participants}

The ATMoSPHAERE study was designed as a longitudinal intervention and feasibility study and was approved by the ethics committee at the Technische Universität Dresden (approval number EK 1012016). The study was performed in the two largest cities in Saxony (Dresden, Leipzig). GP practices from a network of accredited academic teaching practices were included to facilitate recruitment of elderly, multimorbid individuals.

\section{Recruitment of study participants}

General practitioners The GP practices were located in the urban area and each belonged to the practice network mentioned above. Study nurses presented the study during network meetings and encouraged interested GPs to participate. Willing GPs were informed in detail about the study and signed a declaration of consent.

Study participants Individuals who met inclusion criteria (Table 1) were informed about the study by their GP. Eligibility of individuals was assessed by applying validated instruments measuring cognition (Mini-Mental State Examination, MMSE [46], and clock-drawing test [47]), mobility (Timed "Up \& Go" test, TUG) [48] and their independence in everyday life activities (Instrumental Activities of Daily Living assessment) [49]. If eligible individuals decided to participate in the study, they signed a declaration of consent and were informed about the possibility to withdraw their participation at any time.

After inclusion, participants were assessed with regard to possible depression using the validated measuring instrument Geriatric Depression Scale (GDS) [50]. According to the results of the MMSE and the GDS, participants were assigned to risk groups (RGs), as shown in Table 2. RGs were defined as such if mental disorders could make it more difficult for the elderly participant to operate the TMA. The study focused on two of the most common mental syndromes in old age: depression and cognitive impairment [51]. The following specific inclusion criteria were applied:

\section{Description of the TMA and the GP treatment regimen}

The TMA consisted of the telemonitoring hardware ASUS ZenPad 7.0, Samsung Tab 4, sphygmomanometer, pulse oximeter, body weight scale, and the telemonitoring software Motiva and was provided by the technical project partner Philips Medical Systems GmbH.

Sociodemographic and health data of new participants were collected by study assistants and then transferred to a Care Coordination Centre (CCC). Then a technician from the $\mathrm{CCC}$ instructed participants in their homes on the use of 
Table 1 Inclusion and exclusion criteria

\begin{tabular}{|c|c|}
\hline Inclusion criteria & Exclusion criteria \\
\hline Age $\geq 65$ years & Missing capacity of consent \\
\hline Multimorbidity (presence of at least two chronic diseases) & Individuals who cannot speak German fluently \\
\hline $\begin{array}{l}\text { Individuals are capable of understanding participant information } \\
\text { and consented to the study }\end{array}$ & Moderate to severe dementia according to ICD-10 or MMSE $<20$ \\
\hline $\begin{array}{l}\text { Independent operation of television via remote control and/or com- } \\
\text { puter/laptop } \geq 3 \text { times per week }\end{array}$ & $\begin{array}{l}\text { Motoric impairment (TUG: } \geq 30 \mathrm{~s} \text { in initial measurement, } 20-29 \mathrm{~s} \text { in two } \\
\text { repetition measurements) }\end{array}$ \\
\hline Unimpaired hearing & Severe psychiatric comorbidities (e.g. schizophrenic psychoses, addictions) \\
\hline Sufficient motoric and sensory speech ability & $\begin{array}{l}\text { Currently participating in a comparable telemonitoring program or partici- } \\
\text { pation within the last } 12 \text { months }\end{array}$ \\
\hline
\end{tabular}

ICD International Classification of Diseases, MMSE Mini-Mental State Examination, TUG timed “up \& go" test

Table 2 Specific inclusion criteria—risk groups

\begin{tabular}{ll}
\hline Risk group & Specific inclusion criteria \\
\hline 1 & No clinically relevant mental disorder: GDS $\leq 5$ and MMSE $\geq 27$ \\
2 & Clinically relevant affective disorder (depression): GDS $\geq 6$ and MMSE $\geq 27$ \\
3 & Clinically relevant mild cognitive impairment: MMSE 26-20 and GDS $\leq 5$ \\
4 & Clinically relevant affective disorder (depression) and clinically relevant \\
& mild cognitive impairment: GDS $\geq 6$ and MMSE 26-20 \\
\hline
\end{tabular}

GDS Geriatric Depression Scale; MMSE Mini-Mental State Examination the TMA and they had to carry out the first complete measurement and transfer process of their vital data in presence of the technician. After confirmation of having understood the use of the TMA, the care process started. More detailed description of the telemedicine care process for participants has already been described in a previously published paper [52].

According to treatment regimens of participating GPs, participants measured their blood pressure (BP), heart frequency $(\mathrm{HF})$, blood oxygen saturation $\left(\mathrm{SpO}_{2}\right)$, and body weight (BWT) via measuring devices. The frequency of these vital sign measurements was individually determined by each participant's GP (once weekly, 2-6 times per week, and daily). Vital sign data were transferred from measuring devices to the tablet and to the CCC, which constantly monitored and critically assessed the data for intervention necessity. If any limit values were exceeded, control questionnaires were sent to the participant and a care coordinator contacted the participant by telephone. If intervention was required, the GP was provided with relevant information immediately.

For each participant and vital sign, each complete calendar week may be evaluated with respect to the relationship between actual and recommended frequencies of measurement (see supplement (Table S1)). We classified a participant as exactly adherent in a certain calendar week if both the number of days with measurements and the total number of measurements were in line with GP recommendations.
The calendar week was classified as over-measured if the number of days with measurements and/or the total number of measurements was higher than recommended by the GP. In contrast, the calendar week was classified as undermeasured if the number of days with measurements and/or the total number of measurements was lower than recommended by the GP.

\section{Data collection and measures}

To examine changes of participants' HRQoL and symptoms of depression between $t_{0}$ (baseline, installation of TMA), $t_{1}$ (after six months with TMA), and $t_{2}$ (after 12 months with TMA), participants were interviewed by a research scientist via telephone using the validated questionnaires SF-12 [53] and the GDS [50]. The SF-12 was used in the present study to measure HRQoL. The questionnaire covers eight domains of health that are summarized in two summary scores, the PCS and the MCS, both including six items. The scores of the HRQoL domains range from 0 to 100 , with higher scores referring to higher quality of life [54]. Several studies have reported the good psychometric properties of the SF-12 in different age groups and specifically in elderly persons [55]. The GDS consists of 15 questions whose sum score differentiates depressive and non-depressive individuals. Research on screening performance in the elderly showed that the use of the GDS allows an appropriate screening of the very old 
individuals and a reliable detection of a major depression [56].

Data from BP and BWT measurements as recommended by GPs served as the basis for evaluating participant engagement. Due to limited participant and time coverage, two measurement types (heart frequency and blood oxygen saturation) were not included in the analysis.

\section{Statistical analysis}

Baseline characteristics of study participants were analyzed descriptively. Data on measurements/transfer of vital data were also analyzed descriptively regarding frequencies of engagement with measurements, over-measurement, and under-measurement over time (classification according to supplement (Table S1)). Relationships between HRQoL and risk group membership were visualized by box plots. Statistical significance of differences between risk groups regarding HRQoL was tested using Wilcoxon rank-sum tests for unpaired samples. Bivariate associations between participant engagement with blood pressure and body weight measurements, sociodemographic characteristics and PCS / MCS scores at baseline were investigated using the Spearman's rank correlation test and the Kruskal-Wallis test, respectively. Relationships between HRQoL and participant characteristics were investigated using panel data on the PCS and the MCS gathered at baseline $\left(\mathrm{t}_{0}\right)$, at the six-month follow-up $\left(\mathrm{t}_{1}\right)$, and the 12-month follow-up $\left(t_{2}\right)$. To explore associations between HRQoL and covariates, linear multilevel regressions were conducted using the PCS and the MCS as dependent variables and participant characteristics as covariates. In addition to the covariates, the right-hand side of these models contains a random intercept at the participant level. This random intercept captures correlation of the participants' outcomes over time. To explore potential relationships between changes in HRQoL and participants engagement with measurements, linear multilevel regression models for changes in the PCS scores and the MCS scores between $t_{0}$ and $t_{1}$, and $t_{1}$ and $t_{2}$, respectively, were specified. The share of calendar weeks between the PCS and the MCS measurements in which a participant either followed the recommendations of the physician exactly or measured more often than recommended (over-measured) was included as a covariate capturing active study participation. The rationale behind pooling engagement with exact measurement and overmeasurement was that both might be expected to be associated with a higher HRQoL relative to a limited study participation as reflected by under-measurement. Hence, exact and overmeasurement were combined to generate a single binary indicator capturing active study participation. Sensitivity analyses were conducted by treating the shares of calendar weeks classified as exact or over-measured as separate variables (see supplement (Table S2)). Associations were estimated separately for study participants measuring BP and BWT, respectively.
All estimates were adjusted for participant characteristics. Significance levels of $5 \%$ and $1 \%$ were reported for all regression analyses. Statistical analysis was performed using the statistical software IBM SPSS Statistics for Windows v25.0 (IBM Corp., Armonk, NY) and R v3.6.1.

\section{Results}

\section{Sample description}

\section{General practitioners}

We recruited a total of nine general practitioners from the network practices. Three general practitioners worked in Dresden, six general practitioners worked in Leipzig.

\section{Study participants}

At both study sites, a total of 257 participants were assessed for eligibility by performing the Geriatric Basic Assessment (Fig. 1). 177 of the 257 screened participants (68.9\%) were finally included in the study corresponding to the inclusion criteria. A total of 80 participants screened for study inclusion refused study participation (non-participation, $31.1 \%$ ). Of the 177 included participants, data from $80(45.2 \%)$ study participants could not be considered for the engagement analysis in advance due to dropout before installation of the TMA (20; $11.3 \%)$, dropout after installation of the TMA $(11 ; 6.2 \%)$, the end of study before the last survey date $(7 ; 4.0 \%)$, or incomplete SF-12 data $(42 ; 23.7 \%)$.

More detailed information on the demographic data of the study participants can also be found in previously published papers [52, 57].

In the sample of analyzed study participants, the MCS scores were higher than the PCS scores at baseline (Table 3). According to the German Norming Sample, the mean scores for both sexes at the age of 70 and over is 41.69 (SD 12.1) for the PCS and 52.44 (SD 9.9) for the MCS [54]. Most study participants were required to measure both BP and BWT. Participants were unevenly distributed across RGs, with RG 4 including only four participants. Women accounted for more than $60 \%$ of all participants.

\section{Differences in HRQoL between risk groups and changes in HRQoL over time}

Descriptive analyses of the changes in the physical and mental HRQoL of the participants showed differences between the risk groups (Fig. 2). Statistically significant differences could be determined using Wilcoxon rank-sum tests (see supplement (Table S3)).

The results indicate that the median PCS score of study participants with no depression or MCI (RG 1) remained 


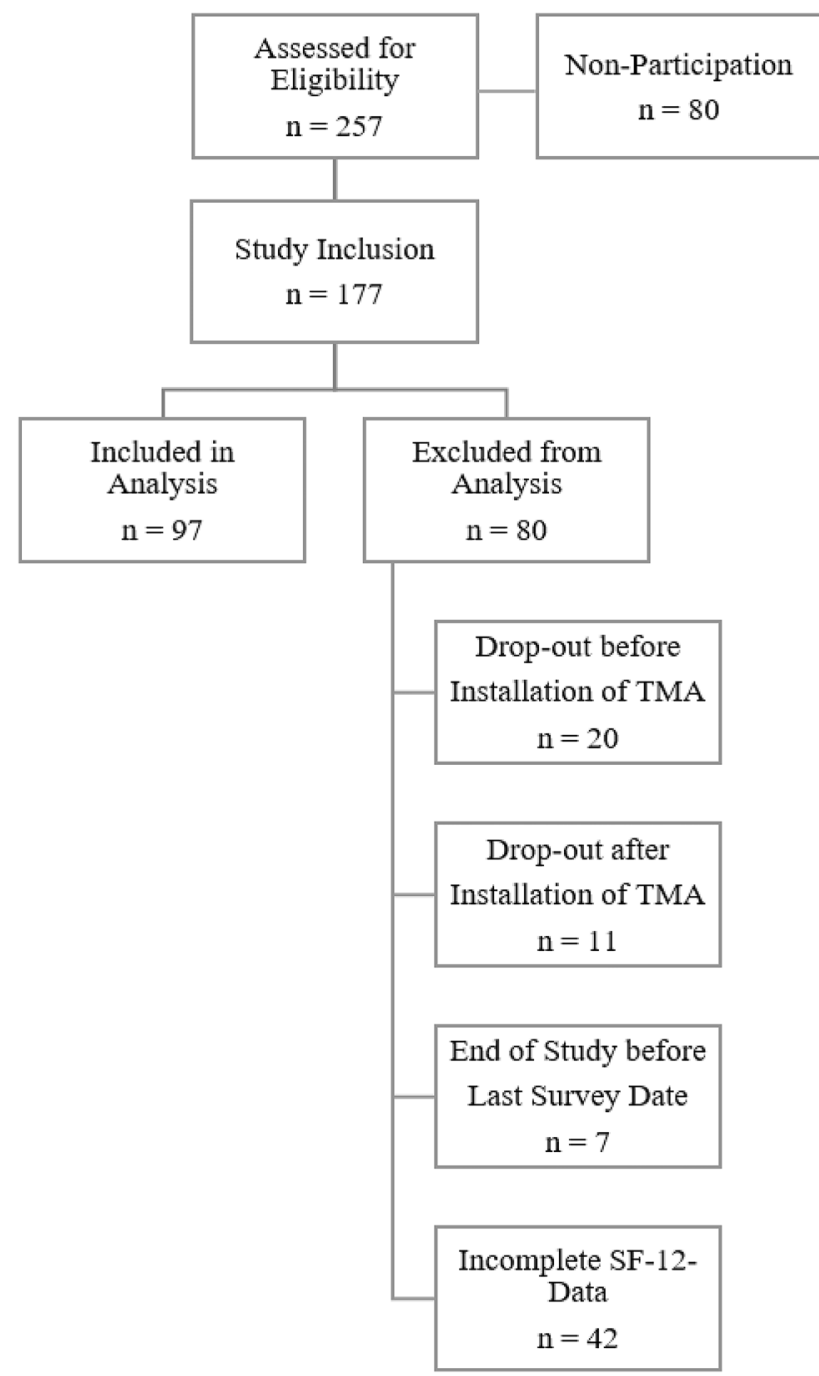

Fig. 1 Flowchart of participant recruitment

stable over time and was consistently higher than in study participants with mental disorders (RG 2, RG 3, RG 4). Study participants with MCI only (RG 3) differed only slightly in their median PCS score from RG 1, although this group of study participants showed fluctuations in the median PCS scores over time. Overall, study participants with depression had lower median scores for the PCS than RG 1 and RG 3, but fluctuated only slightly over time. Study participants with both depression and MCI (RG 4) had the lowest median PCS scores at baseline. Their median PCS scores fluctuated over time, but were similar to the median scores of the study participants in RG 2. Statistically significant differences regarding physical HRQoL of participants were found at $\mathrm{t}_{0}$ (baseline) between RG 1 and RG 2 $(p=0.0013)$ and between RG 1 and RG $4(p=0.003)$. After six months of using the TMA $\left(\mathrm{t}_{1}\right)$, statistically significant differences in RG 1 compared to RG $2(p=0.001)$, RG 3 $(p=0.024)$ and RG $4(p=0.017)$ were found. At $t_{2}$ there
Table 3 Baseline characteristics of analyzed study participants $(n=97)$

\begin{tabular}{|c|c|c|}
\hline Participant characteristics & $n /$ Median & $\% / \mathrm{Q} ;$ Q3 \\
\hline MCS, median (Q1; Q3) & 55.9 & $50.2 ; 59.9$ \\
\hline PCS, median (Q1; Q3) & 43.5 & $32.4 ; 50.4$ \\
\hline \multicolumn{3}{|l|}{ Vital signs, $n(\%)$} \\
\hline Blood pressure only & 30 & $30.9 \%$ \\
\hline Body weight only & 2 & $2.1 \%$ \\
\hline Both & 65 & $67.0 \%$ \\
\hline \multicolumn{3}{|l|}{ Risk group, $n(\%)$} \\
\hline $\begin{array}{l}\text { 1: Participants free of clinically relevant } \\
\text { mental disorders }\end{array}$ & 67 & $69.1 \%$ \\
\hline 2: Participants with depression & 10 & $10.3 \%$ \\
\hline 3: Participants with MCI & 16 & $16.5 \%$ \\
\hline 4: Participants with depression and MCI & 4 & $4.1 \%$ \\
\hline \multicolumn{3}{|l|}{ Age group, $n(\%)$} \\
\hline $65-74$ & 21 & $21.6 \%$ \\
\hline $75-85$ & 63 & $64.9 \%$ \\
\hline $86+$ & 13 & $13.4 \%$ \\
\hline \multicolumn{3}{|l|}{ Sex, $n(\%)$} \\
\hline Male & 37 & $38.1 \%$ \\
\hline Female & 60 & $61.9 \%$ \\
\hline \multicolumn{3}{|l|}{ School education, $n(\%)$} \\
\hline Low $(<10$ years $)$ & 44 & $45.4 \%$ \\
\hline Medium (10 years) & 19 & $19.6 \%$ \\
\hline High (11-13 years) & 34 & $35.1 \%$ \\
\hline \multicolumn{3}{|l|}{ Marital status, $n(\%)$} \\
\hline Alone/widowed & 38 & $39.2 \%$ \\
\hline Married/cohabiting & 59 & $60.8 \%$ \\
\hline
\end{tabular}

Q1 1st quartile, Q3 3rd quartile

were statistically significant differences in RG 1 compared to RG $2(p<0.001)$ and to RG $4(p=0.005)$ and between RG 2 and RG $3(p=0.048)$.

The MCS score showed a similar picture in the distribution between the risk groups, although study participants' mental HRQoL scores were higher than the physical HRQoL scores. Participants from RG 1 also showed the highest MCS overall scores as well as the highest MCS scores over time, with the highest median MCS score of all risk groups at time point $t_{2}$. Participants from RG 3 differed only slightly from the median MCS scores of the RG 1 study participants and remained nearly stable over time. Study participants with depression (RG 2) had slightly lower median scores, although their scores also changed only slightly over time. As with regard to the PCS score, the study participants from RG 4 had the lowest median MCS score at baseline; however, this increased over time and became similar to the MCS scores of the participants from RG 2. With regard to the MCS at $\mathrm{t}_{0}$, RG 4 showed statistically significant differences to RG $1(p=0.006)$ and to RG $3(p=0.022)$. In 
Fig. 2 Changes in PCS and MCS scores between risk groups and over time. RG $1=$ participants free of clinically relevant mental disorders, $\mathrm{RG}$ $2=$ participants with depression, RG 3 = participants with MCI, RG $4=$ participants with depression and MCI. Scores in the boxplot had not yet been adjusted for other variables (e.g. gender) and considered only those study participants who had complete measurements over all three measurement times

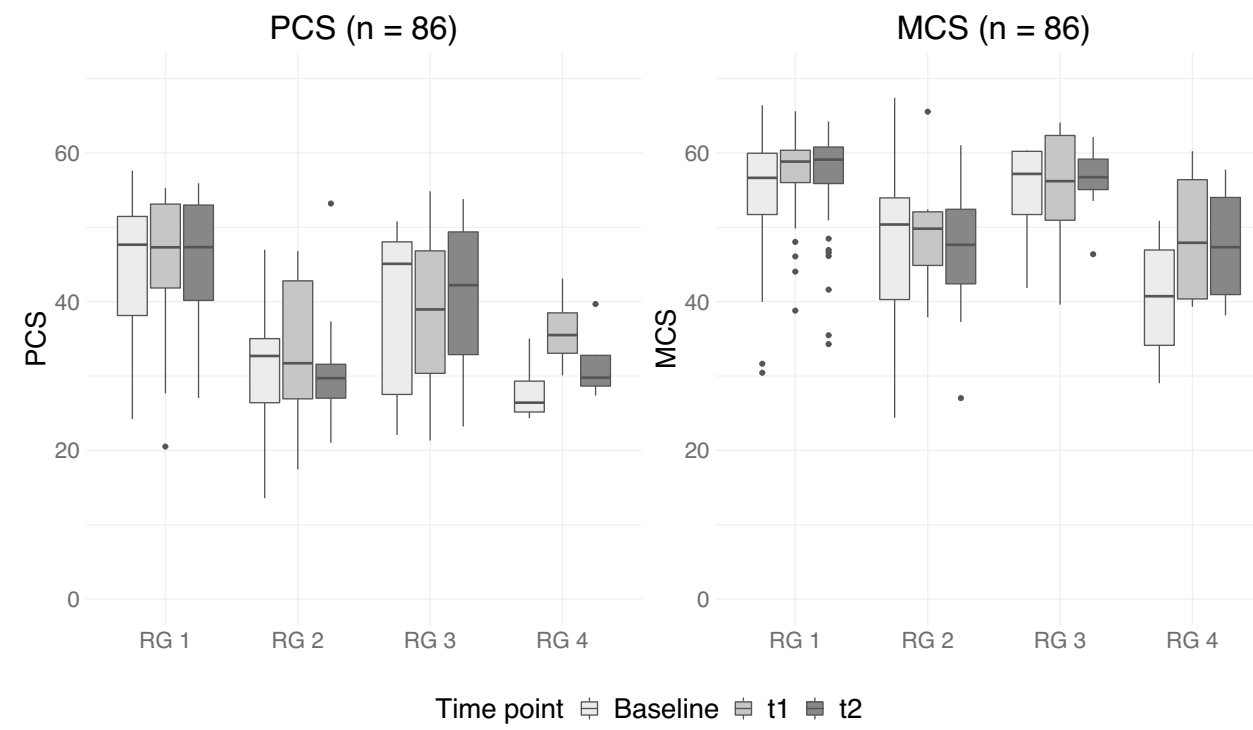

addition, statistically significant differences between RG 1 and RG $2(p<0.001)$ after six months of TMA usage $\left(\mathrm{t}_{1}\right)$ were found. At $t_{2}$ there were statistically significant differences between RG 1 and RG $2(p=0.001)$, RG 1 and RG 4 $(p=0.023)$, as well as between RG 2 and RG $3(p=0.015)$.

The descriptive results withstand an adjustment for other potential covariates of PCS and MCS. Linear mixed effects regression results for the PCS and the MCS levels as dependent variables showed significant differences between risk groups (Table 4). Relative to study participants with no mental disorders (RG 1), study participants with depression (RG 2) and with both depression and MCI (RG 4) had significantly lower PCS and MCS scores. Compared to RG 1, no significant differences were found for participants with only MCI (RG 3). Higher age was associated with lower PCS and MCS scores. Female participants had lower MCS scores than male participants but did not differ significantly from the latter with respect to the PCS scores. The estimation results did not provide evidence for associations between school education and marital status. While the PCS did not differ between study dates $\left(t_{0}, t_{1}, t_{2}\right)$, there was evidence for an increase of the MCS over time as reflected by the positive and statistically significant coefficients of the indicator variables for $t_{1}$ and $t_{2}$.

\section{Associations between participant engagement with measurements and changes in HRQoL scores}

The linear mixed effects regressions for changes in the PCS scores and the MCS scores over time provided evidence for different relationships between the PCS, the MCS, and TMA usage (Table 5). The share of calendar weeks in which a study participant was exact or measured more often than recommended was not associated with changes in the PCS.
This finding holds for both BP and BWT. On the contrary, a higher share of exact or over-measured calendar weeks was significantly related to an increase in the MCS over time. Relative to a study participant that measured BP less than recommended in all calendar weeks, a participant that measured as recommended or more often in all calendar weeks was estimated to experience an MCS increase of approximately 3 points. A similar positive and significant association was found for changes in the MCS and BWT measurement with an estimated effect size of 5.8 points. With respect to the other covariates, there was little evidence for significant relationships with changes in the PCS or the MCS.

We found no statistically significant associations between engagement with blood pressure or body weight measurements and risk group assignment, sociodemographic characteristics or HRQoL at baseline (see supplement (Table S4)).

\section{Discussion}

The present study included participants aged 65 years or older with and without depression and/or MCI. We provide important findings for telemedicine research in elderly, multimorbid individuals and changes in their HRQoL over the course of home-based TMA usage while considering an exact measurement behavior of the participants.

Compared to the mean scores of the PCS and the MCS of the German Norming Sample for individuals of both sexes aged 70 years and over (PCS score: 41.69; SD 12.1/ MCS score: 52.44; SD 9.9) [54], our study cohort showed slightly higher mean scores in both the PCS score and the MCS score (PCS score: 42.47; SD 9.9 / MCS score: 55.02; SD 7.7). For MCS, it could be shown that the results of a 
Table 4 Coefficient estimates from linear mixed effects regressions for levels of the PCS and the MCS with 95\% confidence intervals

\begin{tabular}{|c|c|c|}
\hline Covariate/dependent variable & PCS & MCS \\
\hline $\begin{array}{l}\text { Risk group: } \\
\text { RG 1: Participants free of clinically relevant mental } \\
\text { disorders (Ref.) }\end{array}$ & - & - \\
\hline RG 2: Participants with depression & $\begin{array}{l}-9.39 * * \\
(-15.07,-3.70)\end{array}$ & $\begin{array}{l}-6.22 * * \\
(-9.99,-2.53)\end{array}$ \\
\hline RG 3: Participants with MCI & $\begin{array}{l}-4.40 \\
(-8.90,0.11)\end{array}$ & $\begin{array}{l}-0.48 \\
(-3.49,2.53)\end{array}$ \\
\hline RG 4: Participants with depression and MCI & $\begin{array}{l}-9.83^{*} \\
(-18.09,-1.58)\end{array}$ & $\begin{array}{l}-9.39 * * \\
(-14.82,-3.95)\end{array}$ \\
\hline Age group: 65-74 (Ref.) & - & - \\
\hline $75-85$ & $\begin{array}{l}-4.24 * \\
(-8.21,-0.26)\end{array}$ & $\begin{array}{l}-1.31 \\
(-3.94,1.33)\end{array}$ \\
\hline $86+$ & $\begin{array}{l}-9.35^{* *} \\
(-15.27,-3.43)\end{array}$ & $\begin{array}{l}-4.50^{*} \\
(-8.45,-0.55)\end{array}$ \\
\hline Sex: male (Ref.) & - & - \\
\hline Female & $\begin{array}{l}1.14 \\
(-2.50,4.78)\end{array}$ & $\begin{array}{l}-2.45^{*} \\
(-4.87,-0.04)\end{array}$ \\
\hline School education: Low (Ref.) & - & - \\
\hline Medium & $\begin{array}{l}-0.35 \\
(-4.89,4.19)\end{array}$ & $\begin{array}{l}1.71 \\
(-1.29,4.70)\end{array}$ \\
\hline High & $\begin{array}{l}1.02 \\
(-2.66,4.69)\end{array}$ & $\begin{array}{l}0.54 \\
(-1.90,2.98)\end{array}$ \\
\hline Marital status: alone/widowed (Ref.) & - & - \\
\hline Married/cohabiting & $\begin{array}{l}2.56 \\
(-1.24,6.36)\end{array}$ & $\begin{array}{l}-1.53 \\
(-4.06,0.99)\end{array}$ \\
\hline Time point: baseline $-\mathrm{t}_{0}$ (Ref.) & - & - \\
\hline$t_{1}$ & $\begin{array}{l}1.29 \\
(-0.26,2.83)\end{array}$ & $\begin{array}{l}2.03^{*} \\
(0.40,3.65)\end{array}$ \\
\hline$t_{2}$ & $\begin{array}{l}1.07 \\
(-0.55,2.68)\end{array}$ & $\begin{array}{l}1.77 * \\
(0.08,3.47)\end{array}$ \\
\hline Constant & $\begin{array}{l}45.09 * * \\
(39.21,50.96)\end{array}$ & $\begin{array}{l}58.15^{* *} \\
(54.20,62.11)\end{array}$ \\
\hline Number of observations & 280 & 280 \\
\hline Number of participants & 97 & 97 \\
\hline SD of random intercept & 7.04 & 3.82 \\
\hline
\end{tabular}

$S D$ standard deviation

Significance levels: $* p \leq 0.05, * * p \leq 0.01$ telephone interview were 2.4 scale points higher than those of a postal survey [54]. Therefore, it cannot be assumed that the physical and mental HRQoL of our participants differ from that of the norming sample. In participants with depression (RG 2), as well as in participants with both depression and MCI (RG 4), our study detected significantly lower PCS and MCS scores compared to participants without those mental comorbidities (RG 1). Previous studies examined the association between multimorbidity and HRQoL and showed that multimorbidity is adversely related more to a reduced physical HRQoL than mental HRQoL [5, $26,58]$. Our findings are in line with these results, showing a negative association between multimorbidity and a reduced physical HRQoL, but we also showed a decreased mental HRQoL in our multimorbid participants with depression as well as with both depression and MCI. However, this did not apply to our participants with no mental disorders (RG 1). There were no differences in the PCS and MCS scores between participants with MCI only (RG 3) and participants with no mental disorders (RG 1). The lack of difference could be due to the fact that participants with MCI were partially supported by spouses or other family members in the operation of the TMA and therefore received no change in their HRQoL, e.g. in relation to a physical or emotional 
Table 5 Coefficient estimates from linear mixed effects regressions for changes of the PCS and the MCS with 95\% confidence intervals

\begin{tabular}{|c|c|c|c|c|}
\hline \multirow{2}{*}{$\begin{array}{l}\text { Covariate/dependent variable } \\
\text { Body weight: share of calendar weeks exact or over-measured }\end{array}$} & \multicolumn{2}{|l|}{ Change in PCS } & \multicolumn{2}{|l|}{ Change in MCS } \\
\hline & $\begin{array}{l}-0.003 \\
(-4.79,4.79)\end{array}$ & $\begin{array}{l}- \\
-\end{array}$ & $\begin{array}{l}5.87 * * \\
(1.67,10.06)\end{array}$ & $\begin{array}{l}- \\
-\end{array}$ \\
\hline Blood pressure: share of calendar weeks exact or over-measured & $\begin{array}{l}- \\
-\end{array}$ & $\begin{array}{l}1.11 \\
(-1.84,4.05)\end{array}$ & - & $\begin{array}{l}2.94 * \\
(0.24,5.63)\end{array}$ \\
\hline $\begin{array}{l}\text { Risk group: } \\
\text { RG 1: Participants free of clinically relevant mental disorders (Ref.) }\end{array}$ & - & - & - & - \\
\hline RG 2: Participants with depression & $\begin{array}{l}-2.76 \\
(-8.32,2.80)\end{array}$ & $\begin{array}{l}-0.78 \\
(-5.24,3.68)\end{array}$ & $\begin{array}{l}-0.99 \\
(-5.86,3.88)\end{array}$ & $\begin{array}{l}-3.54 \\
(-7.63,0.55)\end{array}$ \\
\hline RG 3: Participants with MCI & $\begin{array}{l}0.62 \\
(-3.68,4.92)\end{array}$ & $\begin{array}{l}0.39 \\
(-3.21,3.98)\end{array}$ & $\begin{array}{l}-0.79 \\
(-4.55,2.98)\end{array}$ & $\begin{array}{l}-0.73 \\
(-4.02,2.57)\end{array}$ \\
\hline RG 4: Participants with depression and MCI & $\begin{array}{l}0.2 \\
(-6.37,6.76)\end{array}$ & $\begin{array}{l}1.35 \\
(-4.85,7.55)\end{array}$ & $\begin{array}{l}1.48 \\
(-4.27,7.24)\end{array}$ & $\begin{array}{l}1.23 \\
(-4.46,6.92)\end{array}$ \\
\hline Age group: $65-74$ (Ref.) & - & - & - & - \\
\hline $75-85$ & $\begin{array}{l}-0.48 \\
(-4.70,3.75)\end{array}$ & $\begin{array}{l}0.14 \\
(-3.02,3.29)\end{array}$ & $\begin{array}{l}1.91 \\
(-1.79,5.61)\end{array}$ & $\begin{array}{l}-0.31 \\
(-3.20,2.59)\end{array}$ \\
\hline $86+$ & $\begin{array}{l}-1.31 \\
(-7.28,4.67)\end{array}$ & $\begin{array}{l}-0.73 \\
(-5.49,4.04)\end{array}$ & $\begin{array}{l}-2.23 \\
(-7.47,3.00)\end{array}$ & $\begin{array}{l}-3.38 \\
(-7.75,0.99)\end{array}$ \\
\hline Sex: male (Ref.) & - & - & - & - \\
\hline Female & $\begin{array}{l}-0.06 \\
(-3.93,3.81)\end{array}$ & $\begin{array}{l}0.98 \\
(-1.85,3.81)\end{array}$ & $\begin{array}{l}1.04 \\
(-2.35,4.43)\end{array}$ & $\begin{array}{l}0.52 \\
(-2.07,3.12)\end{array}$ \\
\hline School education: Low (Ref.) & - & - & - & - \\
\hline Medium & $\begin{array}{l}-1.15 \\
(-6.17,3.86)\end{array}$ & $\begin{array}{l}-1.08 \\
(-4.55,2.38)\end{array}$ & $\begin{array}{l}2.39 \\
(-2.01,6.78)\end{array}$ & $\begin{array}{l}0.83 \\
(-2.35,4.01)\end{array}$ \\
\hline High & $\begin{array}{l}-1.1 \\
(-4.56,2.36)\end{array}$ & $\begin{array}{l}-0.79 \\
(-3.75,2.17)\end{array}$ & $\begin{array}{l}-0.31 \\
(-3.34,2.72)\end{array}$ & $\begin{array}{l}-1.68 \\
(-4.40,1.03)\end{array}$ \\
\hline Marital status: alone/widowed (Ref.) & - & - & - & - \\
\hline Married/cohabiting & $\begin{array}{l}-1.03 \\
(-4.95,2.90)\end{array}$ & $\begin{array}{l}1.04 \\
(-1.92,3.99)\end{array}$ & $\begin{array}{l}-0.88 \\
(-4.32,2.55)\end{array}$ & $\begin{array}{l}-1.97 \\
(-4.68,0.74)\end{array}$ \\
\hline Constant & $\begin{array}{l}2.63 \\
(-3.81,9.06)\end{array}$ & $\begin{array}{l}-0.72 \\
(-5.39,3.96)\end{array}$ & $\begin{array}{l}-1.02 \\
(-6.66,4.61)\end{array}$ & $\begin{array}{l}2.16 \\
(-2.13,6.45)\end{array}$ \\
\hline Number of observations & 123 & 180 & 123 & 180 \\
\hline Number of participants & 67 & 95 & 67 & 95 \\
\hline SD of random intercept & 0 & 0 & 0 & 0 \\
\hline
\end{tabular}

$S D$ standard deviation

Significance levels: $* p \leq 0.05, * * p \leq 0.01$

role function. However, especially participants with mental disorders, e.g. those with depression and/or MCI, may benefit from individual and tailored solutions [42] in the care provided by the GP [59], such as an appropriate TMA. In order to keep HRQoL and engagement with measurements constant over time, participants should be closely involved as co-designers and experts in the development process of future telemonitoring projects [60]. Especially participants with MCI can benefit from participating in telemonitoring development processes. Being appreciated for their contribution can strengthen their confidence and empowerment, stabilize cognitive ability and positively shape their illness experience. Pointing out needs which should be especially considered for this target group provides a great added value for implementation of projects with individuals suffering from mental disorders [60, 61].

Further results from the present study indicated that female participants had a lower MCS score than male participants. No gender differences in the PCS scores were found, nor did the participants differ in the PCS and MCS scores in terms of educational level or marital status. Various studies have shown that older women have a lower interest in technology, use less technology and have less confidence in their own abilities when compared to older men when it comes to operating the technology [62-64]. Female participants may not be able to experience greater empowerment 
or self-efficacy as a result. We examined participants aged 65 and over who had at least two chronic diseases. Our results indicate that higher age was not only associated with a reduced PCS score but also with a reduced MCS score. Reduced physical and mental HRQoL can be attributed to the perceived burden of disease, which increases with age and makes it considerably more difficult for participants to maintain and manage various activities in daily life [10]. It should be noted, however, that the TMA examined was able to support participants in closely monitoring their state of health and giving them a feeling of security, which in our study is expressed in a significantly better MCS score over time. However, this type of TMA can also reach limits, e.g. when elderly people can no longer cope with life on their own due to progressive diseases.

Associations between exact and over-measuring participants and changes in their HRQoL over the study time could be detected: Participants who were exact in their BP and BWT measurements or had even measured more often than recommended by the GP had a significantly better evolution of the MCS than the participants who measured less often. Positive significant associations had been detected between MCS scores and BWT measurements over time. Since the devices for vital data measurement were always available in the participants' homes, the participants had the opportunity to carry out measurements at their own discretion and thus to control their own state of health. This possibility could have increased the feeling of security and empowerment in the participants [65], which is associated with an increased mental HRQoL. The increase in the MCS scores over time can also be due to the fact that participants may have felt more comfortable with the closely focused care through project participation and more empowered through self-management of their own health care [66, 67]. These benefits were also reported in other home telemonitoring studies [68, 69]. Higher MCS scores in elderly, chronically ill people had also been shown in an RCT that compared telemonitoring and usual care [19]. Another explanation could be that our study participants who showed an increased mental HRQoL over time could better motivate themselves to use the TMA. However, no association between changes in PCS score over time and engagement of participants with measurements was found. This finding is in accordance with former RCTs that investigated home-based TMAs in elderly, chronically ill individuals [24, 25]. Also here, no changes in physical HRQoL over time were observed.

\section{Limitations and strengths}

Our study sample is a non-representative convenience sample. Eligible individuals were easily accessible and recruitable via the participating GPs. Selection bias could exist, as the GPs and the individuals voluntarily participated in the study. We conducted telephone interviews with the participants to assess their HRQoL and possible depression over time using the SF-12 questionnaire and the GDS, respectively. The SF-36 and the GDS have been validated for interviews $[54,70]$. A comparison of the survey types with the SF-36 showed that the results for the MCS score in telephone interviews were 2.4 scale points higher than in the postal survey [54]. This may be associated with a tendency towards social desirability among respondents, which could result in a response bias [54]. Participants may have behaved differently because they knew that they were participating in a study and were under observation (Hawthorne effect). By implementing a randomized controlled study design, statements about the effectiveness of the telemonitoring intervention used would have been possible. However, that design was not used in the present study.

We were able to include a vulnerable target group relevant for telemedicine research in our study: multimorbid individuals aged 65 years and over with mental comorbidities. Even if the risk groups examined are not large in number, the results provide important information about the changes in physical and mental HRQoL of these target groups. The results obtained complement the research area of telemedicine applications in elderly people.

\section{Conclusion}

Our feasibility study showed that depression and the coexistence of depression and MCI are negatively associated with HRQoL of elderly, multimorbid people using a TMA. Engagement of individuals with vital data measurements via telemonitoring applications which are in line with the treatment regimen of the GP may increase the mental HRQoL, but not the physical HRQoL of individuals. An increased HRQoL of individuals can be a decisive factor in their constant engagement with telemonitoring measures. In order to examine the effectiveness of future telemonitoring interventions, randomized controlled study designs must be applied. Future research should focus on further determinants that can influence the usability of telemedicine applications for mentally impaired people.

Supplementary Information The online version contains supplementary material available at https://doi.org/10.1007/s11136-021-02848-8.

Author contributions CL conducted interviews with study participants and maintained research data obtained. CL and MR prepared the data for analysis. CL drafted the manuscript with considerable input for statistical analysis by MR. VH, AB and JS participated in the overall study design and implementation. All authors read and commented on the first draft of the manuscript and approved the final version.

Funding Open Access funding enabled and organized by Projekt DEAL. The German Federal Ministry of Education and Research 
supported the development of the presented telemedicine system within the funding program "Medical Technology Solutions for Multimorbidity" (grant number 13GW0075F). The funding body had no role in the design of the study, in collection, analysis, or interpretation of data or in writing the manuscript.

Data availability The data of the study are not available for public use; data are owned by the ATMoSPHAERE consortium and the authors are not allowed to share them with third parties.

Code availability Statistical analysis was performed using the statistical software IBM SPSS Statistics for Windows v25.0 (IBM Corp., Armonk, NY) and R v3.6.1.

\section{Declarations}

Conflict of interest The authors declared no potential conflicts of interest with respect to the research, authorship and/or publication of this article.

Ethical approval The ethics committee at the Technische Universität Dresden (approval number EK 1012016) approved the study presented. All study participants gave written informed consent before participating in the study.

Open Access This article is licensed under a Creative Commons Attribution 4.0 International License, which permits use, sharing, adaptation, distribution and reproduction in any medium or format, as long as you give appropriate credit to the original author(s) and the source, provide a link to the Creative Commons licence, and indicate if changes were made. The images or other third party material in this article are included in the article's Creative Commons licence, unless indicated otherwise in a credit line to the material. If material is not included in the article's Creative Commons licence and your intended use is not permitted by statutory regulation or exceeds the permitted use, you will need to obtain permission directly from the copyright holder. To view a copy of this licence, visit http://creativecommons.org/licenses/by/4.0/.

\section{References}

1. Fuchs, J., Busch, M., Lange, C., \& Scheidt-Nave, C. (2012). Prevalence and patterns of morbidity among adults in Germany. Bundesgesundheitsblatt, Gesundheitsforschung, Gesundheitsschutz, 55(4), 576-586. https://doi.org/10.1007/s00103-012-1464-9

2. Marengoni, A., Angleman, S., Melis, R., Mangialasche, F., Karp, A., Garmen, A., et al. (2011). Aging with multimorbidity: A systematic review of the literature. Ageing Research Reviews, 10(4), 430-439. https://doi.org/10.1016/j.arr.2011.03.003.

3. World Health Organization. (2016). Multimorbidity. World Health Organization. Retrieved June 28, 2018 from https://apps.who.int/ iris/handle/10665/252275. Lizenz: CC BY-NC-SA 3.0 IGO.

4. Rechel, B., Grundy, E., Robine, J. M., Cylus, J., Mackenbach, J. P., Knai, C., et al. (2013). Ageing in the European Union. The Lancet, 381(9874), 1312-1322. https://doi.org/10.1016/s0140-6736(12) 62087-x.

5. Fortin, M., Bravo, G., Hudon, C., Lapointe, L., Almirall, J., Dubois, M. F., et al. (2006). Relationship between multimorbidity and health-related quality of life of patients in primary care. Quality of Life Research, 15(1), 83-91. https://doi.org/10.1007/ s11136-005-8661-z.
6. Ehling, R. (2013). Gesundheitsbezogene Lebensqualität (HRQoL). In T. Berger, M. Linneban, \& H. Wiendl (Eds.), Betaferon. Springer.

7. Rotenstein, L. S., Huckman, R. S., \& Wagle, N. W. (2017). Making patients and doctors happier-The potential of patientreported outcomes. New England Journal of Medicine, 377(14), 1309-1312. https://doi.org/10.1056/NEJMp1707537.

8. Czypionka, T., \& Achleitner, S. (2018). Patient reported outcome and experience measures. Soziale Sicherheit, 10(3), 16.

9. Wiering, B., de Boer, D., \& Delnoij, D. (2017). Patient involvement in the development of patient-reported outcome measures: A scoping review. Health Expectations, 20(1), 11-23. https://doi. org/10.1111/hex.12442.

10. Palladino, R., Tayu Lee, J., Ashworth, M., Triassi, M., \& Millett, C. (2016). Associations between multimorbidity, healthcare utilisation and health status: Evidence from 16 European countries. Age and Ageing, 45(3), 431-435. https://doi.org/10.1093/ ageing/afw044.

11. Kadam, U. T., \& Croft, P. R. (2007). Clinical multimorbidity and physical function in older adults: A record and health status linkage study in general practice. Family Practice, 24(5), 412-419. https://doi.org/10.1093/fampra/cmm049.

12. Gu, J., Chao, J., Chen, W., Xu, H., Zhang, R., He, T., et al. (2018). Multimorbidity and health-related quality of life among the community-dwelling elderly: A longitudinal study. Archives of Gerontology and Geriatrics, 74, 133-140. https://doi.org/10. 1016/j.archger.2017.10.019.

13. Knox, L., Rahman, R. J., \& Beedie, C. (2017). Quality of life in patients receiving telemedicine enhanced chronic heart failure disease management: A meta-analysis. Journal of Telemedicine and Telecare, 23(7), 639-649. https://doi.org/10.1177/13576 $33 \times 16660418$.

14. WHO Global Observatory for eHealth. (2010). Telemedicine: opportunities and developments in Member States: report on the second global survey on eHealth. World Health Organization. Retrieved June 28, 2018 from https://apps.who.int/iris/handle/ $10665 / 44497$

15. Bundesärztekammer. (2015). Telemedizinische Methoden in der Patientenversorgung-Begriffliche Verortung. Retrieved December 12, 2018 from http://www.bundesaerztekammer.de/ aerzte/telematiktelemedizin/telemedizin/.

16. Augustin, U., \& Henschke, C. (2012). Does telemonitoring lead to health and economic benefits in patients with chronic heart failure? A systematic review. Gesundheitswesen, 74(12), e114121. https://doi.org/10.1055/s-0032-1309021

17. McDowell, J. E., McClean, S., Fitzgibbon, F., \& Tate, S. (2015). A randomised clinical trial of the effectiveness of home-based health care with telemonitoring in patients with COPD. Journal of Telemedicine and Telecare, 21(2), 80-87. https://doi.org/10. 1177/1357633x14566575

18. Polisena, J., Tran, K., Cimon, K., Hutton, B., McGill, S., \& Palmer, K. (2009). Home telehealth for diabetes management: A systematic review and meta-analysis. Diabetes, Obesity \& Metabolism, 11(10), 913-930. https://doi.org/10.1111/j.14631326.2009.01057.x

19. Cichosz, S. L., Udsen, F. W., \& Hejlesen, O. (2019). The impact of telehealth care on health-related quality of life of patients with heart failure: Results from the Danish TeleCare North heart failure trial. Journal of Telemedicine and Telecare. https:// doi.org/10.1177/1357633x19832713

20. Goldberg, L. R., Piette, J. D., Walsh, M. N., Frank, T. A., Jaski, B. E., Smith, A. L., et al. (2003). Randomized trial of a daily electronic home monitoring system in patients with advanced heart failure: The Weight Monitoring in Heart Failure (WHARF) trial. American Heart Journal, 146(4), 705-712. https://doi.org/10.1016/s0002-8703(03)00393-4. 
21. Valdivieso, B., Garcia-Sempere, A., Sanfelix-Gimeno, G., Faubel, R., Librero, J., Soriano, E., et al. (2018). The effect of telehealth, telephone support or usual care on quality of life, mortality and healthcare utilization in elderly high-risk patients with multiple chronic conditions A prospective study. Medicina Clinica (Barc). https://doi.org/10.1016/j.medcli.2018.03.013.

22. Bohingamu Mudiyanselage, S., Stevens, J., Watts, J. J., Toscano, J., Kotowicz, M. A., Steinfort, C. L., et al. (2019). Personalised telehealth intervention for chronic disease management: A pilot randomised controlled trial. Journal of Telemedicine and Telecare, 25(6), 343-352. https://doi.org/10.1177/1357633×18 775850 .

23. Noel, H. C., Vogel, D. C., Erdos, J. J., Cornwall, D., \& Levin, F. (2004). Home telehealth reduces healthcare costs. Telemedicine Journal and E-Health, 10(2), 170-183. https://doi.org/10.1089/ tmj.2004.10.170

24. Antoniades, N. C., Rochford, P. D., Pretto, J. J., Pierce, R. J., Gogler, J., Steinkrug, J., et al. (2012). Pilot study of remote telemonitoring in COPD. Telemedicine Journal and E-Health, 18(8), 634-640. https://doi.org/10.1089/tmj.2011.0231.

25. Gingele, A. J., Ramaekers, B., Brunner-La Rocca, H. P., De Weerd, G., Kragten, J., van Empel, V., et al. (2019). Effects of tailored telemonitoring on functional status and health-related quality of life in patients with heart failure. Netherlands Heart Journal, 27(11), 565-574. https://doi.org/10.1007/s12471-019-01323-X.

26. Pecina, J. L., Hanson, G. J., Van Houten, H., \& Takahashi, P. Y. (2013). Impact of telemonitoring on older adults health-related quality of life: The Tele-ERA study. Quality of Life Research, 22(9), 2315-2321. https://doi.org/10.1007/s11136-013-0361-5

27. Maresca, G., De Cola, M. C., Caliri, S., De Luca, R., Manuli, A., Scarcella, I., et al. (2019). Moving towards novel multidisciplinary approaches for improving elderly quality of life: The emerging role of telemedicine in Sicily. Journal of Telemedicine and Telecare, 25(5), 318-324. https://doi.org/10.1177/1357633x17 753057.

28. Villani, A., Malfatto, G., Compare, A., Della Rosa, F., Bellardita, L., Branzi, G., et al. (2014). Clinical and psychological telemonitoring and telecare of high risk heart failure patients. Journal of Telemedicine and Telecare, 20(8), 468-475. https://doi.org/10. 1177/1357633x14555644.

29. Poon, P., Hui, E., Dai, D., Kwok, T., \& Woo, J. (2005). Cognitive intervention for community-dwelling older persons with memory problems: Telemedicine versus face-to-face treatment. International Journal of Geriatric Psychiatry, 20(3), 285-286. https:// doi.org/10.1002/gps.1282

30. Gellis, Z. D., Kenaley, B. L., \& Ten Have, T. (2014). Integrated telehealth care for chronic illness and depression in geriatric home care patients: The Integrated Telehealth Education and Activation of Mood (I-TEAM) study. Journal of the American Geriatrics Society, 62(5), 889-895. https://doi.org/10.1111/jgs.12776

31. Vincent, C., Reinharz, D., Deaudelin, I., Garceau, M., \& Talbot, L. R. (2006). Public telesurveillance service for frail elderly living at home, outcomes and cost evolution: A quasi experimental design with two follow-ups. Health and Quality of Life Outcomes, 4, 41. https://doi.org/10.1186/1477-7525-4-41

32. Schofield, R. S., Kline, S. E., Schmalfuss, C. M., Carver, H. M., Aranda, J. M. Jr., Pauly, D. F., et al. (2005). Early outcomes of a care coordination-enhanced telehome care program for elderly veterans with chronic heart failure. Telemedicine Journal and E-Health, 11(1), 20-27. https://doi.org/10.1089/tmj.2005.11.20.

33. Shah, M. N., Wasserman, E. B., Wang, H., Gillespie, S. M., Noyes, K., Wood, N. E., et al. (2016). High-intensity telemedicine decreases emergency department use by senior living community residents. Telemedicine Journal and E-Health, 22(3), 251-258. https://doi.org/10.1089/tmj.2015.0103.
34. Clark, R. A., Yallop, J. J., Piterman, L., Croucher, J., Tonkin, A., Stewart, S., et al. (2007). Adherence, adaptation and acceptance of elderly chronic heart failure patients to receiving healthcare via telephone-monitoring. European Journal of Heart Failure, 9(11), 1104-1111. https://doi.org/10.1016/j.ejheart.2007.07.018.

35. Maeder, A., Poultney, N., Morgan, G., \& Lippiatt, R. (2015). Patient compliance in home-based self-care telehealth projects. Journal of Telemedicine and Telecare, 21(8), 439-442. https:// doi.org/10.1177/1357633x15612382

36. Kerby, T. J., Asche, S. E., Maciosek, M. V., O'Connor, P. J., SperlHillen, J. M., \& Margolis, K. L. (2012). Adherence to blood pressure telemonitoring in a cluster-randomized clinical trial. Journal of Clinical Hypertension (Greenwich, Conn.), 14(10), 668-674. https://doi.org/10.1111/j.1751-7176.2012.00685.x

37. Celler, B., Argha, A., Varnfield, M., \& Jayasena, R. (2018). Patient adherence to scheduled vital sign measurements during home telemonitoring: Analysis of the intervention arm in a before and after trial. JMIR Medical Informatics, 6(2), e15. https://doi.org/10.2196/medinform.9200

38. Thordardottir, B., Malmgren Fänge, A., Lethin, C., Rodriguez Gatta, D., \& Chiatti, C. (2019). Acceptance and use of innovative assistive technologies among people with cognitive impairment and their caregivers: A systematic review. BioMed Research International, 2019, 9196729. https://doi.org/10.1155/ 2019/9196729

39. Holthe, T., Halvorsrud, L., Karterud, D., Hoel, K. A., \& Lund, A. (2018). Usability and acceptability of technology for communitydwelling older adults with mild cognitive impairment and dementia: A systematic literature review. Clinical Interventions in Aging, 13, 863-886. https://doi.org/10.2147/cia.S154717

40. Cavallo, F., Aquilano, M., \& Arvati, M. (2015). An ambient assisted living approach in designing domiciliary services combined with innovative technologies for patients with Alzheimer's disease: A case study. American Journal of Alzheimer's Disease and Other Dementias, 30(1), 69-77. https://doi.org/10.1177/ 1533317514539724

41. Lazar, A., Demiris, G., \& Thompson, H. J. (2015). Involving family members in the implementation and evaluation of technologies for dementia: A dyad case study. Journal of Gerontological Nursing, 41(4), 21-26. https://doi.org/10.3928/00989134-20150309-03

42. Smith, G. E., Lunde, A. M., Hathaway, J. C., \& Vickers, K. S. (2007). Telehealth home monitoring of solitary persons with mild dementia. American Journal of Alzheimer's Disease and Other Dementias, 22(1), 20-26. https://doi.org/10.1177/1533317506 295888

43. van den Berg, N., Schumann, M., Kraft, K., \& Hoffmann, W. (2012). Telemedicine and telecare for older patients-A systematic review. Maturitas, 73(2), 94-114. https://doi.org/10.1016/j. maturitas.2012.06.010

44. Holthoff-Detto, V. (2015). Teilvorhabensbeschreibung zur Bekanntmachung Medizintechnische Lösungen bei Multimorbidität: Evaluation der IT-gestützten ATMoSPHÄRE-Plattform und medizinische Leitung im Design holistischer Versorgungsprogramme. Verbundname: Autonomie trotz Multimorbidität in Sachsen durch Patientenempowerment, Holistische Versorgung für Ältere mit Vernetzung aller Regionalen Einrichtungen und Dienstleister (ATMoSPHÄRE). Unpublished project document.

45. Koch, B. (2015). Gesamtverbundbeschreibung zur Bekanntmachung Medizintechnische Lösungen bei Multimorbidität. Verbundname: Autonomie trotz. Multimorbidität in Sachsen durch Patientenempowerment, Holistische Versorgung für Ältere mit Vernetzung aller Regionalen Einrichtungen und Dienstleister (ATMoSPHÄRE). Unpublished project document.

46. Creavin, S. T., Wisniewski, S., Noel-Storr, A. H., Trevelyan, C. M., Hampton, T., Rayment, D., et al. (2016). Mini-Mental State Examination (MMSE) for the detection of dementia in clinically 
unevaluated people aged 65 and over in community and primary care populations. Cochrane Database of Systematic Reviews. https://doi.org/10.1002/14651858.CD011145.pub2.

47. Shulman, K. I., Pushkar Gold, D., Cohen, C. A., \& Zucchero, C. A. (1993). Clock-drawing and dementia in the community: A longitudinal study. International Journal of Geriatric Psychiatry, 8(6), 487-496

48. Podsiadlo, D., \& Richardson, S. (1991). The timed "Up \& Go": A test of basic functional mobility for frail elderly persons. Journal of the American Geriatrics Society, 39(2), 142-148

49. Lawton, M. P., \& Brody, E. M. (1969). Assessment of older people: Self-maintaining and instrumental activities of daily living. The Gerontologist, 9(3), 179-186

50. Yesavage, J. A., Brink, T. L., Rose, T. L., Lum, O., Huang, V., Adey, M., et al. (1982). Development and validation of a geriatric depression screening scale: A preliminary report. Journal of Psychiatric Research, 17(1), 37-49.

51. Leyhe, T., Reynolds, C. F. III., Melcher, T., Linnemann, C., Klöppel, S., Blennow, K., et al. (2017). A common challenge in older adults: Classification, overlap, and therapy of depression and dementia. Alzheimer's \& Dementia: The Journal of the Alzheimer's Association, 13(1), 59-71. https://doi.org/10.1016/j.jalz. 2016.08.007.

52. Lang, C., Voigt, K., Neumann, R., Bergmann, A., \& HolthoffDetto, V. (2020). Adherence and acceptance of a home-based telemonitoring application used by multi-morbid patients aged 65 years and older. Journal of Telemedicine and Telecare. https:// doi.org/10.1177/1357633x20901400

53. Tarlov, A. R., Ware, J. E., Jr., Greenfield, S., Nelson, E. C., Perrin, E., \& Zubkoff, M. (1989). The Medical Outcomes Study. An application of methods for monitoring the results of medical care. JAMA, 262(7), 925-930

54. Morfeld, M., Kirchberger, I., \& Bullinger, M. (2011). SF-36 Fragebogen zum Gesundheitszustand: Deutsche Version des Short Form-36 Health Survey. Hogrefe Verlag GmbH.

55. Gobbens, R. J., \& Remmen, R. (2019). The effects of sociodemographic factors on quality of life among people aged 50 years or older are not unequivocal: Comparing SF-12, WHOQOL-BREF, and WHOQOL-OLD. Clinical Interventions in Aging, 14, 231239. https://doi.org/10.2147/cia.s189560

56. Marc, L. G., Raue, P. J., \& Bruce, M. L. (2008). Screening Performance of the Geriatric Depression Scale (GDS-15) in a Diverse Elderly Home Care Population. The American Journal of Geriatric Psychiatry, 16(11), 914-921. https://doi.org/10.1097/JGP. 0b013e318186bd67

57. Lang, C., Scheibe, M., Voigt, K., Hubsch, G., Mocke, L., Schmitt, J., et al. (2019). Reasons for non-acceptance and non-use of a home telemonitoring application by multimorbid patients aged 65 years and over. Zeitschrift für Evidenz, Fortbildung und Qualität im Gesundheitswesen, 141-142, 76-88. https://doi.org/10.1016/j. zefq.2019.02.009.

58. Ramond-Roquin, A., Haggerty, J., Lambert, M., Almirall, J., \& Fortin, M. (2016). Different multimorbidity measures result in varying estimated levels of physical quality of life in individuals with multimorbidity: A Cross-Sectional Study in the general population. BioMed Research International, 2016, 78454387845438. https://doi.org/10.1155/2016/7845438

59. Sinnott, C., Mc Hugh, S., Browne, J., \& Bradley, C. (2013). GPs' perspectives on the management of patients with multimorbidity:
Systematic review and synthesis of qualitative research. British Medical Journal Open, 3(9), e003610. https://doi.org/10.1136/ bmjopen-2013-003610

60. Wang, G., Marradi, C., Albayrak, A., \& van der Cammen, T. J. M. (2019). Co-designing with people with dementia: A scoping review of involving people with dementia in design research. Maturitas, 127, 55-63. https://doi.org/10.1016/j.maturitas.2019. 06.003

61. McConnell, T., Sturm, T., Stevenson, M., McCorry, N., Donnelly, M., Taylor, B. J., et al. (2019). Co-producing a shared understanding and definition of empowerment with people with dementia. Research Involvement and Engagement, 5, 19. https://doi.org/10. 1186/s40900-019-0154-2.

62. Tacken, M., Marcellini, F., Mollenkopf, H., Ruoppila, I., \& Széman, Z. (2005). Use and acceptance of new technology by older people: Findings of the international MOBILATE survey "Enhancing mobility in later life." Gerontechnology, 3, 126

63. Doh, M. (2011). Heterogenität der Mediennutzung im Alter. Theoretische Konzepte und empirische Befunde. Band 2: Gesellschaft - Altern - Medien. kopaed Verlags-GmbH, München

64. Broos, A. (2005). Gender and information and communication technologies (ICT) anxiety: Male self-assurance and female hesitation. Cyberpsychology \& Behavior, 8(1), 21-31. https://doi.org/ 10.1089/cpb.2005.8.21

65. van Hoof, J., Kort, H. S. M., Rutten, P. G. S., \& Duijnstee, M. S. H. (2011). Ageing-in-place with the use of ambient intelligence technology: Perspectives of older users. International Journal of Medical Informatics, 80(5), 310-331. https://doi.org/10.1016/j. ijmedinf.2011.02.010

66. Boaz, M., Hellman, K., \& Wainstein, J. (2009). An automated telemedicine system improves patient-reported well-being. Diabetes Technology \& Therapeutics, 11(3), 181-186. https://doi.org/10. 1089/dia.2008.0048

67. Trief, P. M., Teresi, J. A., Izquierdo, R., Morin, P. C., Goland, R., Field, L., et al. (2007). Psychosocial outcomes of telemedicine case management for elderly patients with diabetes: The randomized IDEATel trial. Diabetes Care, 30(5), 1266-1268. https:// doi.org/10.2337/dc06-2476.

68. Rahimpour, M., Lovell, N. H., Celler, B. G., \& McCormick, J. (2008). Patients' perceptions of a home telecare system. International Journal of Medical Informatics, 77(7), 486-498. https:// doi.org/10.1016/j.ijmedinf.2007.10.006

69. Lee, P. A., Greenfield, G., \& Pappas, Y. (2018). Patients' perception of using telehealth for type 2 diabetes management: A phenomenological study. BMC Health Services Research, 18(1), 549. https://doi.org/10.1186/s12913-018-3353-x

70. Allgaier, A.-K., Kramer, D., Mergl, R., Fejtkova, S., \& Hegerl, U. (2011). Validität der Geriatrischen Depressionsskala bei Altenheimbewohnern: Vergleich von GDS-15, GDS-8 und GDS-4. Psychiatrische Praxis, 38(06), 280-286. https://doi.org/10.1055/s0030-1266105

Publisher's Note Springer Nature remains neutral with regard to jurisdictional claims in published maps and institutional affiliations. 